\title{
Modeling the Chain of Conversion for a PV System
}

\author{
Mohammed El Alami ${ }^{1}$, Mohamed Habibi ${ }^{1}$, Seddik Bri ${ }^{2}$ \\ ${ }^{1}$ Laboratory of Systems and Telecommunications Engineering Decision, Sciences Faculty, Ibn tofail University, \\ Kenitra, Morocco \\ ${ }^{2}$ Electrical Engineering Department, High School of Technology, Moulay Ismail University, Meknes, Morocco \\ Email: elalami.ensa@gmail.com
}

Received 1 August 2014; revised 29 August 2014; accepted 8 September 2014

Copyright (C) 2014 by authors and Scientific Research Publishing Inc.

This work is licensed under the Creative Commons Attribution International License (CC BY). http://creativecommons.org/licenses/by/4.0/

(c) (7) Open Access

\begin{abstract}
In this work, we conduct a study of modeling and simulation of a system in the context of renewable energy in general, and solar system "photovoltaic" in particular; also, the optimizing system adapted by DC-DC converters static. Then the influence of temperature and irradiance on the optimal parameters (Power of MPP, VMPP, ...) of a solar system is analyzed in a way to operate a PV generator at its maximum power. This system includes a photovoltaic generator, "Boost \& Buck", converter and a load. Modeling and simulation system (solar panel, DC-DC converter command and load) is obtained through Matlab-Simulink software.
\end{abstract}

\section{Keywords}

Photovoltaic Panel, DC-DC Converter, The Maximum Power Point, Fill Factor

\section{Introduction}

The greater part of the energy consumed currently comes from the use of fossil fuels like oil, coal, natural gas or nuclear power. These resources become increasingly rare while the energy demands of the world amounted continuously. Since this form of energy covers a large part of the current energy production, it is necessary to find an alternative solution to take the relay. The constraint is to use a source of economic power and low emission as the protection of the environment has become an important point. Photovoltaic solar energy is the direct conversion of part of the solar radiation into electrical energy. This energy conversion is affected throughout photovoltaic cell based on a physical phenomenon called the photovoltaic effect, which is to produce a current when the surface of the cell is exposed to light. Science is naturally interested in the "renewable" resources. Photovoltaic solar energy is increasingly used in various terrestrial applications such as lighting and telecommunications [1]. 
The use of solar energy will provide electricity to isolated sites of electrical networks and avoid the creation of new electrical lines which generally requires a heavy investment.

\section{Modeling of the Photovoltaic System}

The PV cell, also called solar cell, constitutes the basic element of the photovoltaic conversion. This is a semiconductor device that converts electric energy into light energy provided by an inexhaustible source of energy and the Sun. It exploits the properties of semiconductor materials used in the electronics industry: diodes, transistors and integrated circuits. Figure 1 illustrates a typical PV cell where its formation is detailed. The performance of energy efficiency achieved industrially are $13 \%$ to $14 \%$ for the cells based on monocrystalline silicon, with $11 \%$ to $12 \%$ of poly crystalline silicon and finally $7 \%-8 \%$ for the amorphous silicon by thin films [2]. The photopile or solar cell is the basic element of a photovoltaic generator, and the equivalent circuit of a PV cell is shown in Figure 2. It includes a current source, a diode, a series resistance and a shunt resistance.

The photovoltaic effect is manifested when a photon is absorbed in a semiconductor material composed of doped $p$ (positive) and $n$ (negative), referred to as $p-n$ junction (or n-p). Under the effect of doping, an electric field is present in the material permanently (like a magnet which has a permanent magnetic field) [3]. When an incident photon (grain of light) interacts with the electrons in the material, it transfers its energy to the electron hv which finds herself liberated from its valence band and therefore suffers the intrinsic electric field. Under the influence of this field, electron migrates toward the top surface leaving a hole that migrates in the reverse direction. Electrodes placed on the upper and lower surfaces allow the electrons to collect them and to make electrical work to join the anterior surface of the hole. A cell is often modeled by the electrical equivalent diagram it is he that is shown in Figure 2, the photovoltaic generator is modeled by the following equations [4]:

$$
\begin{gathered}
I=I_{p h}-I_{s}\left[\exp \left(q \frac{V+I \cdot R_{s}}{A \cdot K \cdot T}\right)-1\right]-\frac{V+I \cdot R_{s}}{R_{s h}} \\
P=V *\left[I_{p h}-I_{s}\left[\exp \left(q \frac{V+I \cdot R_{s}}{A \cdot K \cdot T}\right)-1\right]-\frac{V+I \cdot R_{s}}{R_{s h}}\right]
\end{gathered}
$$

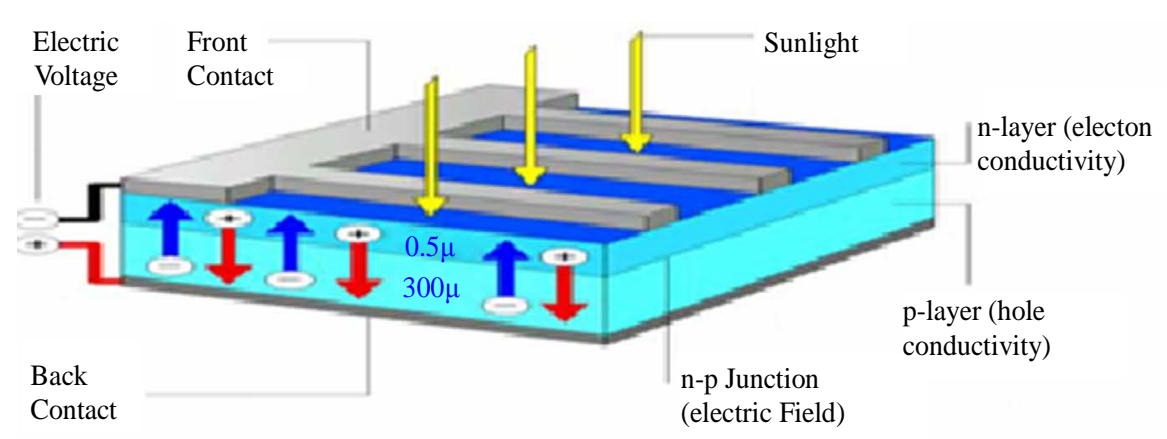

Figure 1. Schématic of a photovoltaic cell.

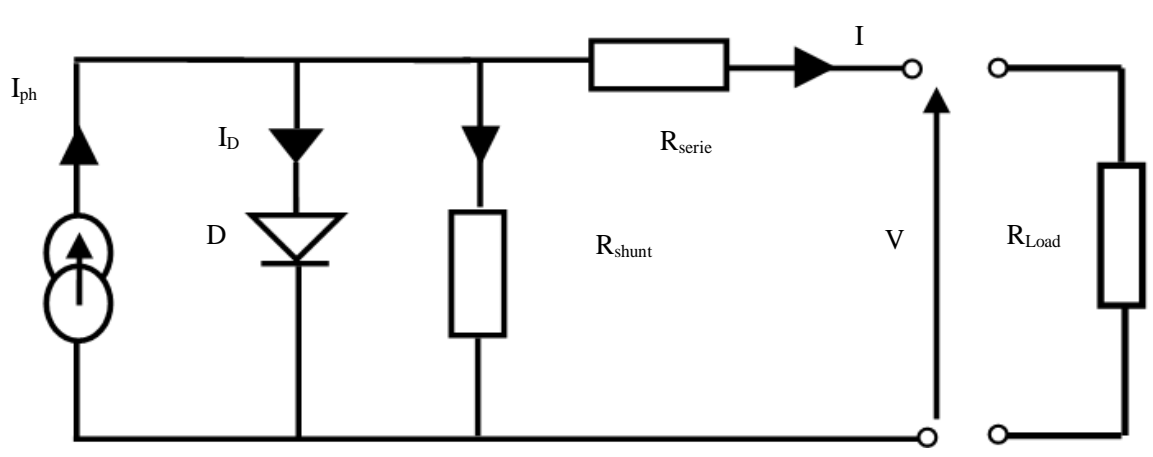

Figure 2. Equivalent circuit of a PV cell. 
with $I_{p h}(\mathrm{~A})$ is currently produced by the cells; $I_{s}(\mathrm{~A})$ is the saturation current; $q=1.6 \times 10^{-19} \mathrm{C}$ load electron; $K=1.38 \times 10^{-23} \mathrm{~J} / \mathrm{K}$ Boltzmann constant; $T\left({ }^{\circ} \mathrm{C}\right)$ is the operating temperature of the cell; $A$ is a quality factor of the diode, normally between 1 and 2; $R_{s}(\Omega)$ and $R_{s h}(\Omega)$ are series and parallel resistors. After the determination of the various parameters of the equivalent circuit, it is possible to solve the equation of characteristic $I=f(\mathrm{~V})$, and also to determine these characteristics (current $I(\mathrm{~A})$, power $P(\mathrm{~W}))$ by numerical method.

\section{The Influence of Meteorological Conditions on the Performance of a PV System}

The characteristic curve of a PV cell represents the variation of the current which it produces as a function of the voltage at its terminals, since the short circuit (zero voltage corresponding to the maximum current product) till the open circuit (no current to a maximum voltage across the cell) [5]. In this case, we chose a simple model, requiring only the parameters given by the manufacturer to evoke the influence of meteorological parameters on the maximum power point, the I-V characteristic of this model is shown in Figure 3, and for influences of the conditions meteorological illustrated in Figure 4 and Figure 5: The electrical characteristics of the photovoltaic module that we used were obtained by numerical simulation of the model by Matlab-Simulink software.

The maximum power $P_{\max }$ suitable for MPP is very susceptible to light as illustrated in Figure 4: when the illumination decreases from $100 \mathrm{~W} / \mathrm{m}^{2}$, power $P_{\max }$ decreases by $10 \%$. With cons, the maximum power $\left(P_{\max }\right)$ decreases little with temperature particularly strong illumination. When the temperature increases from $10^{\circ} \mathrm{C}$ to about the ambient temperature and illumination of $1000 \mathrm{~W} / \mathrm{m}^{2}$ power $P_{\max }$ decreased by $4 \%$.

The optimum voltage $V_{\mathrm{mpp}}$ suitable for MPP varies very little with the illumination and decreases slightly with temperature as illustrated in Figure 5. For illumination of $1000 \mathrm{~W} / \mathrm{m}^{2}$ and around ambient temperature $\left(25^{\circ} \mathrm{C}\right)$ : when the temperature varies from $10^{\circ} \mathrm{C}$, the voltage ranges from $4.2 \%$. These results show that the voltage varies relatively little in the course of the day. Also, it is considered as a first approximation that the optimal operation of PV generator substantially corresponds to operation at constant optimum voltage $V_{\text {mpp }}$.

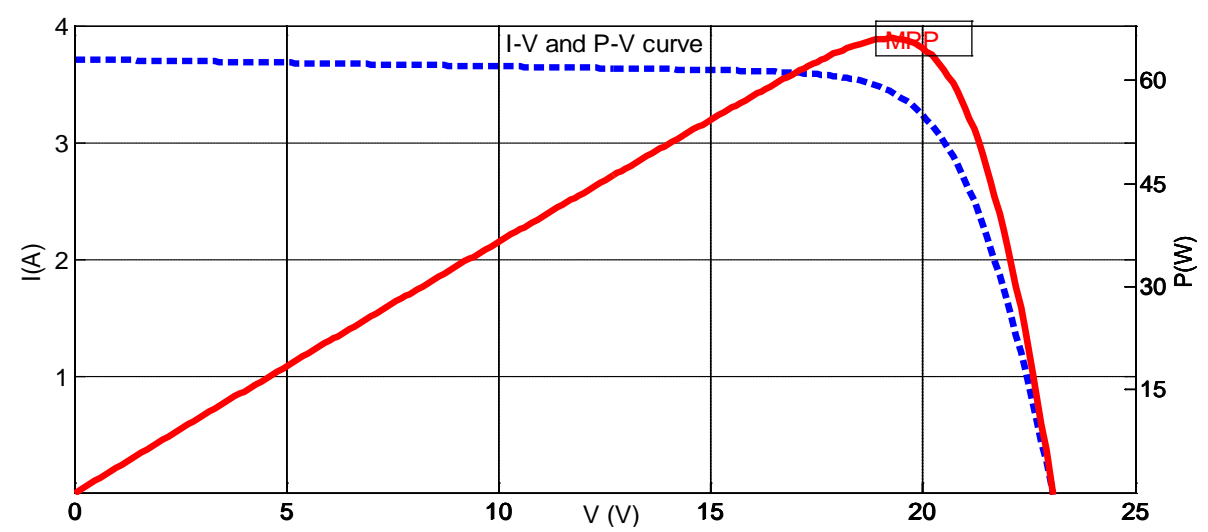

Figure 3. Characteristic current I(V) and Power P(V) of PV Cell.

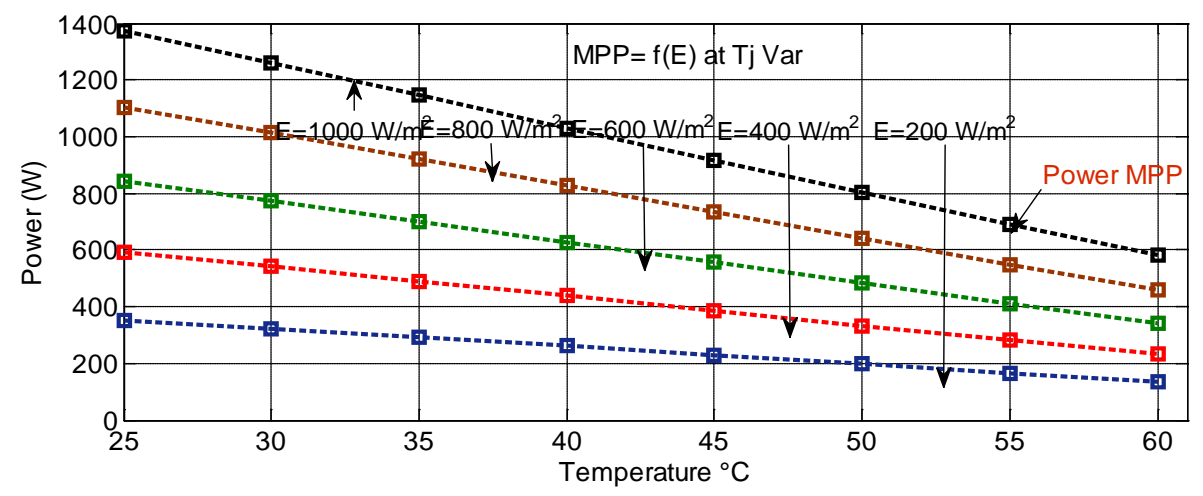

Figure 4. Influence of temperature and illumination on MPP of PV module. 
The coefficient of maximum power point MPP and the optimal voltage linking the measured quantities and optimal variables is not always accurately fixed and little vary with time as a function of aging. It depends in particular on temperature and sunlight as illustrated in Figure 4 and Figure 5.

\section{Adaptation through of DC-DC Converter}

The chopper is a DC-DC converter for converting a DC power to a given level of voltage (or current) in a continuous energy to another level of voltage (or current). Use turns out necessary to store solar energy in batteries or to feed a continuous load equivalent circuit of the chopper is represented by Figure 6 and Figure 7 below. Two topologies of bass conversion circuit (DC/DC), choppers are DC-DC static converters for generating a variable DC voltage source from a source of fixed voltage. The chopper consists of capacitors, inductors and switches. All of these devices in the ideal case do not consume power, this is the reason why the choppers have good yields. Usually the switch is a MOSFET transistor is a semiconductor device mode (block-saturate), for our work we throw a glance on Boost and Buck converters.

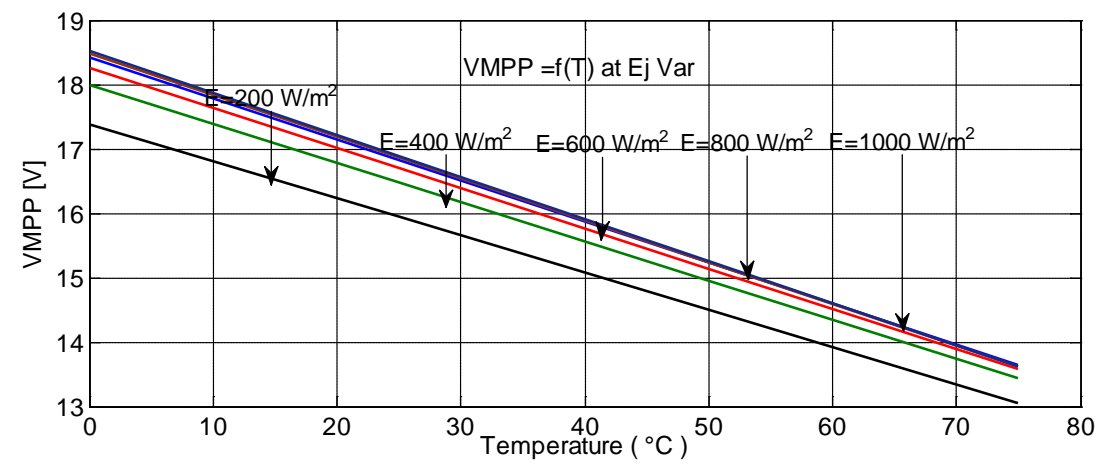

Figure 5. Variation of voltage VMPP according to on the temperature $T$ and illumination E.

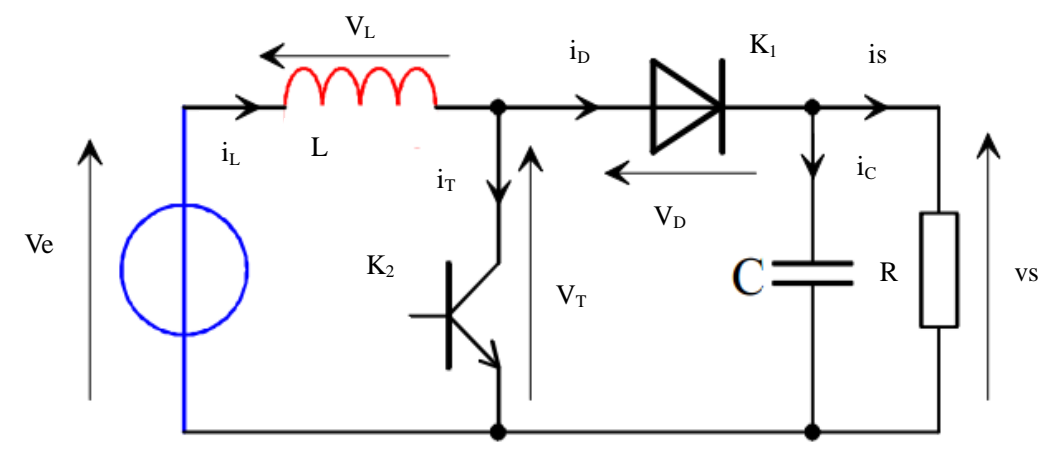

Figure 6. Boost converter.

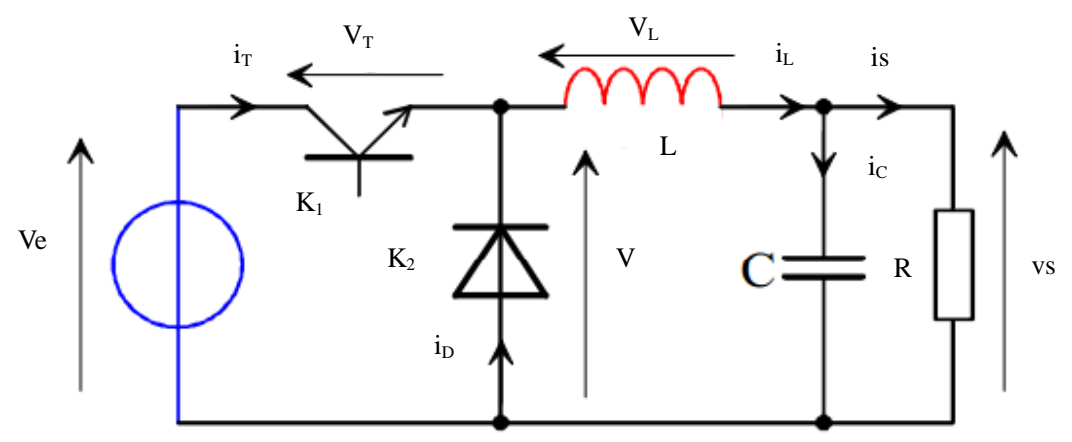

Figure 7. BUCK converter. 


\subsection{Buck \& Boost Converters}

The boost converter is known by the name of voltage booster that can be represented by the circuit of Figure 6 . The boost converter is characterized by the fact that the output voltage is higher than the input voltage [6]. This is a direct DC-DC converter. The input source is DC-type (inductor in series with a voltage source) and output load is of the type voltage (capacitor in parallel with the resistive load). The switch K1 can be replaced by a transistor since the current is always positive and that the switching should be commanded (the Blocking and priming). A buck converter, or series chopper, is a device that converts a DC voltage into another DC voltage of lower value. The buck converter as illustrated in Figure 7 is used in applications where you want to have an output voltage lower than the input voltage [7].

\section{Functioning}

For the BOOST, the switch K1 is closed during the $\alpha T$ fraction of the switching period $T$. The input source provides power to the load $R$ through the inductor $L$. When transistor is blocked, the diode K2 ensures continuity of the current in the inductor. The energy stored in the inductor is then discharged into the capacitor and the resistance of the load. In steady state, the medium value of the terminal voltage of the inductor is zero, which imposes the following equation:

$$
\begin{aligned}
& V_{e}=(1-\alpha) \cdot V_{s} \\
& V_{s}=V_{e} \cdot \frac{1}{(1-\alpha)}
\end{aligned}
$$

From Equation (3), the conversion ratio of boost chopper is given in the following form:

$$
M(\alpha)=\frac{V_{s}}{V_{e}}=\frac{1}{(1-\alpha)}
$$

And for the BUCK converter, the switch K1 is closed during the fraction $T$ of the switching period $T$. The input source provides an power to the load $R$ through the inductance $L$. When the Blocking the transistor, the diode K2 ensures continuity of the current in the inductor. The energy stored in the inductor is then discharged into the capacitor and the load resistor. In steady state, the medium value of the terminal voltage of the inductor is zero. The output voltage is given by the following equation:

$$
V_{s}=V-V_{L}=\alpha \cdot V_{e}
$$

From Equation (6), the conversion ratio of buck chopper is given in the following form:

$$
M(\alpha)=\frac{V_{s}}{V_{e}}=\alpha
$$

After resolution of equations by Matlab can be shown the Figure 8 illustrates the linear relation between the conversion report and the duty ratio and also to Figure 9 shows the evolution of conversion by the duty cycle ratio.

This is Equation (6) which shows that the buck converter is a step-down voltage because the output voltage of the converter equal to the input voltage by a coefficient which varies in the range [0,1] as illustrated in Figure 8 . And Figure 9, in this case it is the Equation (3) shows that the boost converter is a voltage booster.

\subsection{Simulation of the Chopper by Matlab Simulink}

\subsubsection{Chopper Series}

Four demonstrate the role of converters Buck we used Matlab simulation software and we are taking ( $E=300 \mathrm{~V}, L=1 \mathrm{H}, R=30 \Omega$ ). As illustrated in the Figure 10 with the components used and the interconnection between them, by Matlab Simulink.

After having the voltage input $300 \mathrm{~V}$ as shown in the Figure 11, we found the output value $150 \mathrm{~V}$, as illustrated in Figure 12, different and proportional to the duty cycle alpha $\alpha=0.5$, we conclude that the role of boost for a solar system. 


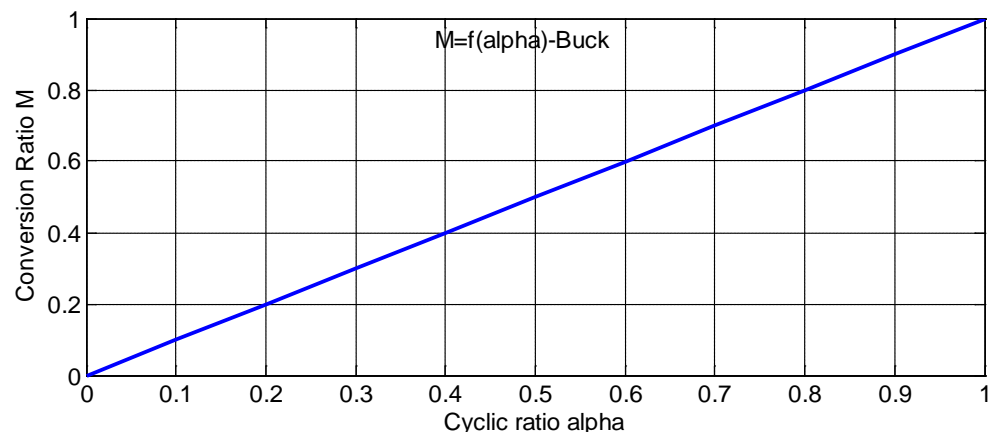

Figure 8. The conversion ratio buck according $\alpha$.

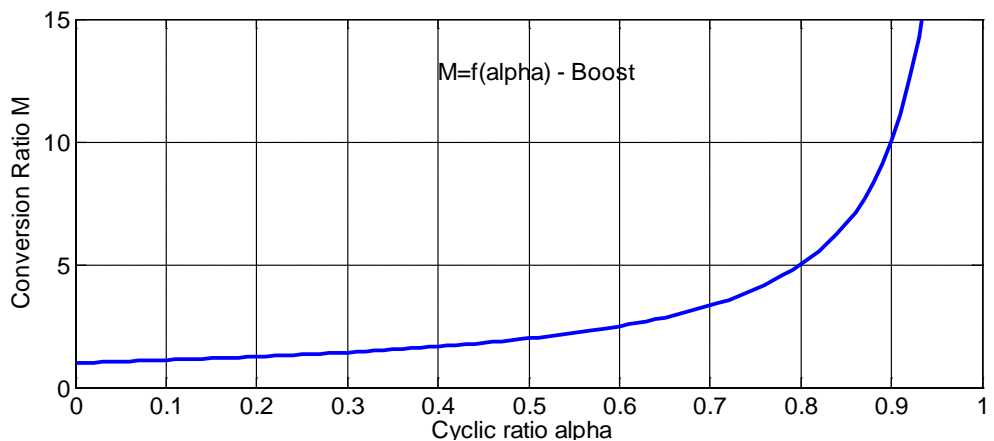

Figure 9. The conversion ratio boost according $\alpha$.

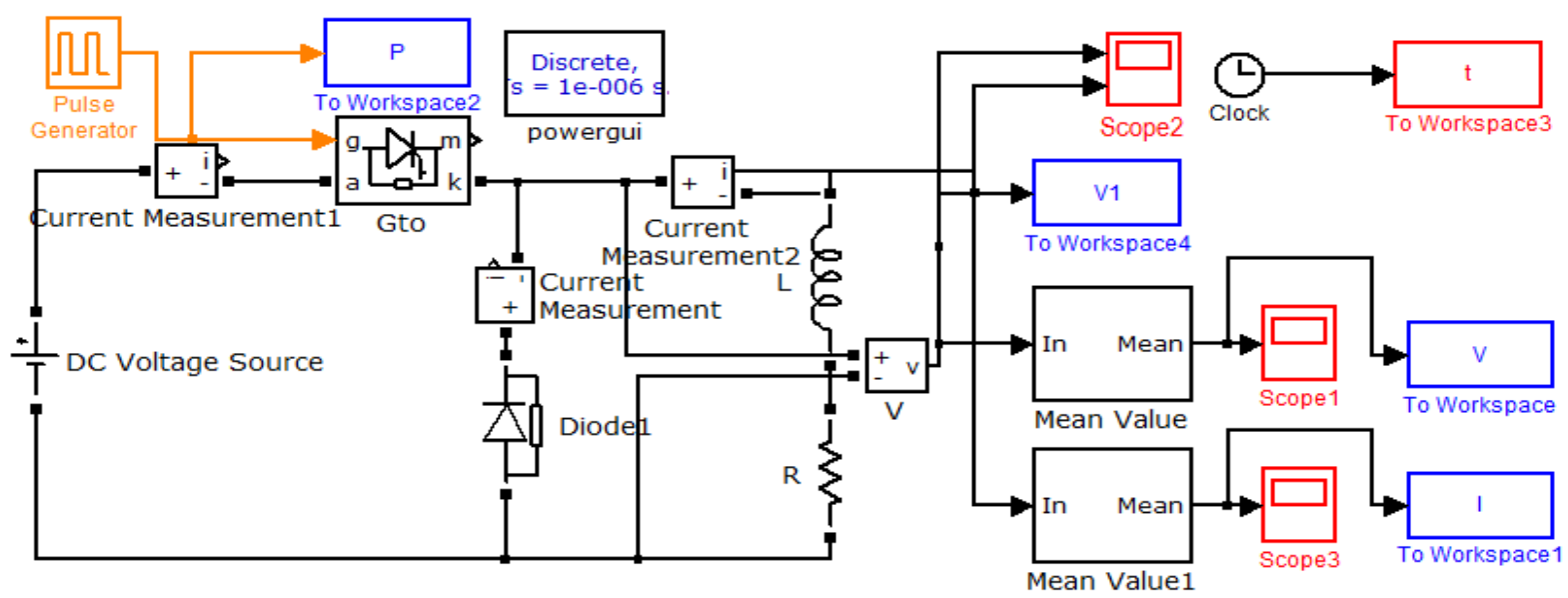

Figure 10. Block diagram of simulation of Buck converter.

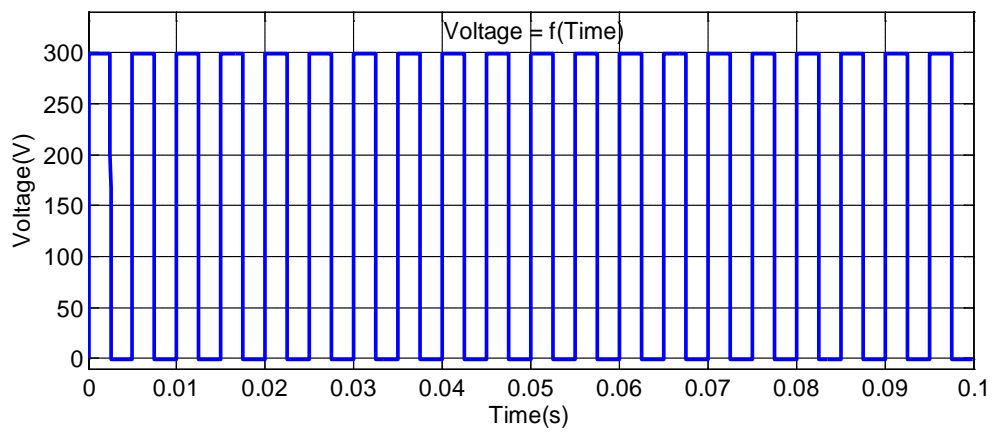

Figure 11. Input voltage to the converter as a function of time. 
And to give several values of voltage as a function of duty cycle which shows the proportionality between the duty cycle and the input voltage and also to express the role of a Buck in Table 1 below shows the variation of the average value of the voltage and current versus duty cycle.

The output voltage of the chopper is not continuous but always be positive. When the time is quite low (frequency $100-1000 \mathrm{~Hz}$ ) the load does not "see" the not slots, but the medium value of the voltage. We notice whatever the nature of the charge, we have $V_{s}=0 \leq \alpha U \leq U$ chopper series is voltage step-down (buck chopper).

\subsubsection{Parallel Chopper}

To show the role of converters boost we used Matlab software for the simulation and we take $(E=24 \mathrm{~V}$, $L=1 \times 10^{-3} \mathrm{H}, \quad R=50 \Omega$ ) as illustrated in Figure 13 .

After the results in Figure 14 it is noted that the output voltage $V_{s} \sim 47 \mathrm{~V}$ is not the same as the input $V_{e} \sim 24 \mathrm{~V}$ for a duty cycle $\alpha=0.5$ which expresses the role of boost converter. It is therefore important to play on the cyclic ratio of a share, and on the other hand, although the inductor $L$ dimension, to get a smooth current to the capacitor $C$ and having a desired output voltage.

\section{Performance of a Chain Photovoltaic}

\subsection{Energy Efficiency}

We recall the definitions of the different yields and measurement conditions thereof. As a result, the overall yield of the conversion chain reflects all sources of losses over the entire PV chain.

The power received by a panel of area $A\left(\mathrm{~m}^{2}\right)$ is equal to $G \cdot A_{\text {eff }}$.

We will take as a definition reflecting performance the maximum capacity of a GPV and quality of the electron-photon conversion of a solar panel noted $\eta_{p v}$, the performance defined by the equation:

$$
\eta_{p v}=\frac{P_{\max }}{A_{\text {eff }} \cdot G}
$$

$P_{\max }$ : The maximum power delivered by the PV generator.

$G$ : irradiance $\left(\mathrm{W} / \mathrm{m}^{2}\right)$ is defined as the amount of solar electromagnetic energy incident on a surface per unit of time and area.

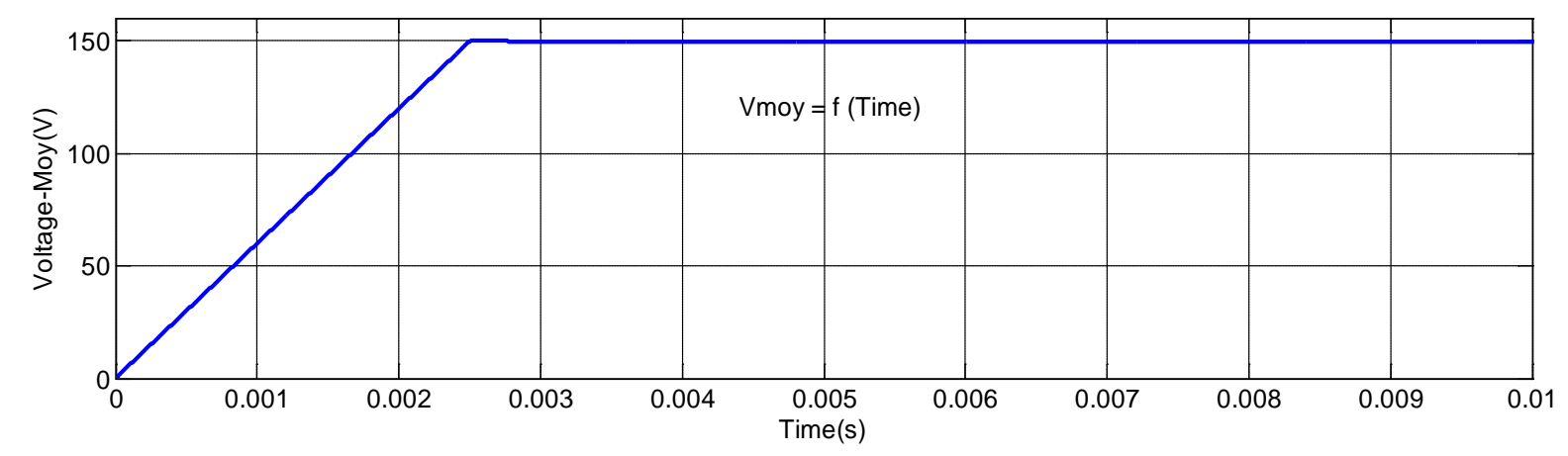

Figure 12. The medium value of the output voltage.

Table 1. The variation of the average value of the voltage and current according $\alpha$.

\begin{tabular}{cccc}
\hline & & Duty Cycle $\alpha$. & 0.40 \\
& & 0.200 .30 & 0.50 \\
$U_{\text {сMоу }}$ & 6289.1 & 118 & 148.5 \\
$I_{\text {с }}$ & 1.9752 .970 & 4.692 & 4.694 \\
\hline
\end{tabular}




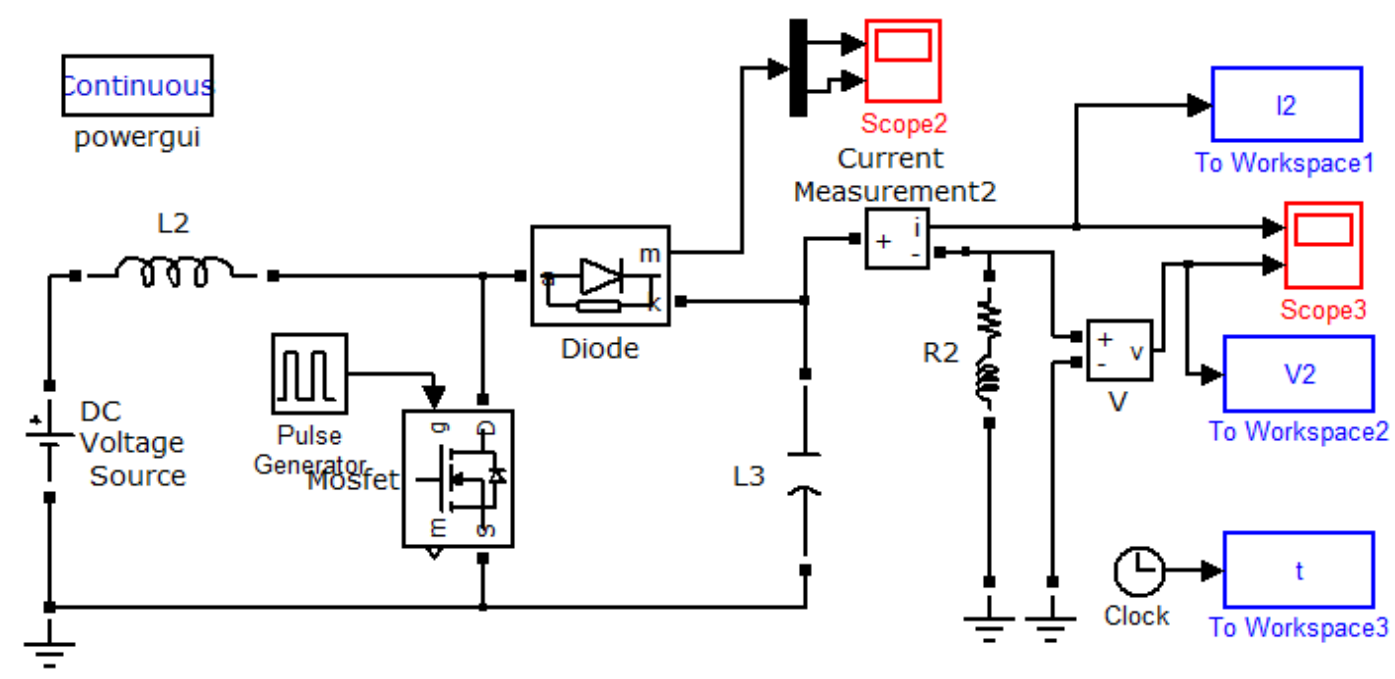

Figure 13. Block diagram of simulation of boost converter.
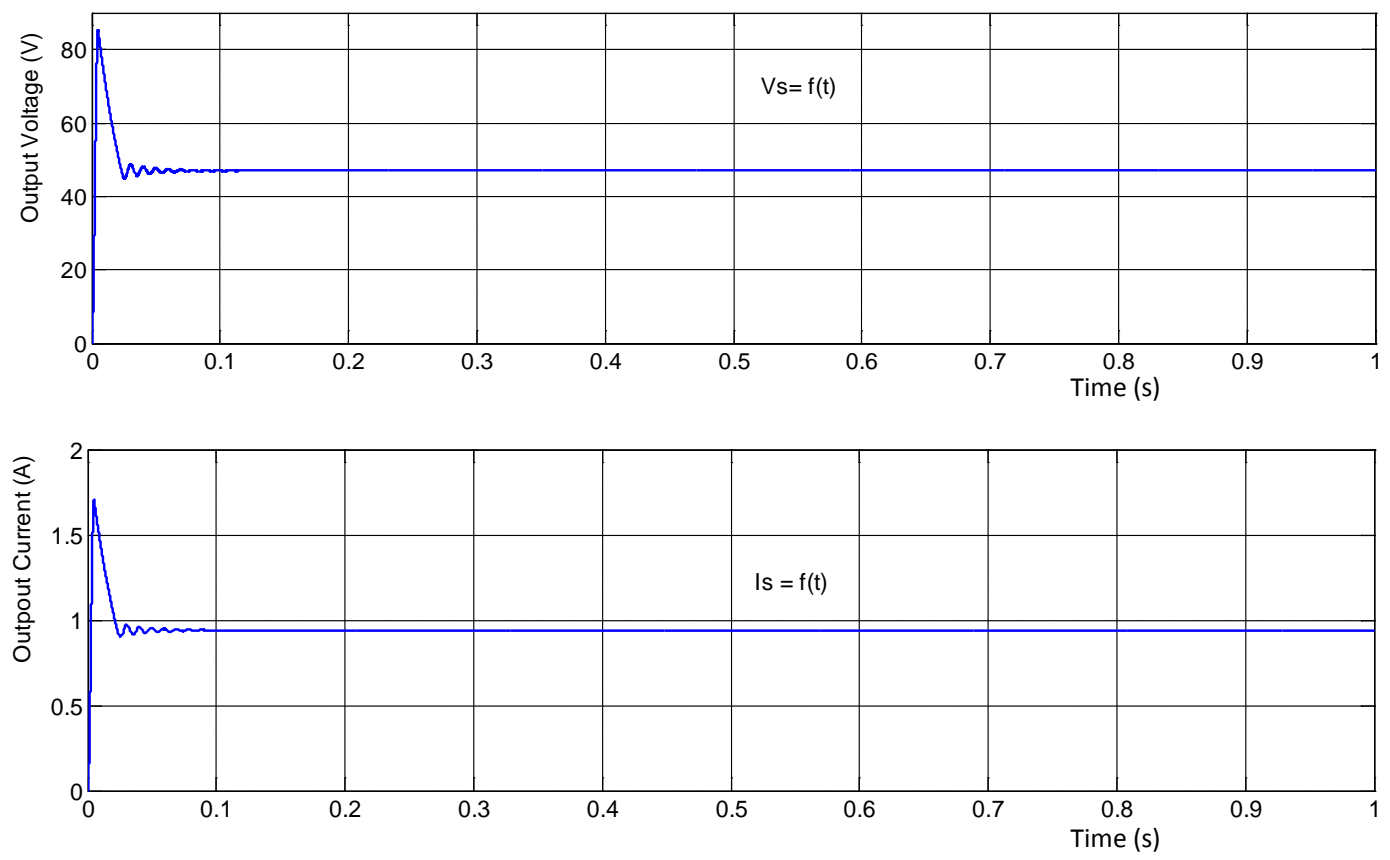

Figure 14. Curve of voltage and current output of the boost converter.

$A_{\text {eff }}$ : Represents the area of the corresponding panel the active part and capable of able to perform of photovoltaic conversion and not the total area occupied by the solar panel.

The power $P$ effectively delivered by an PV generator depends more on the command used in the converter (MPPT voltage control, direct connection, ...). Performance of the operating point which place we note $\eta_{\mathrm{MPPT}}$ can measure the effectiveness of the command that is responsible for the control of static converter so that the $\mathrm{PV}$ module furnish maximum power.

$$
\eta_{\mathrm{MPPT}}=\frac{P}{P_{\max }}=\frac{P}{I_{\mathrm{opt}} \cdot V_{\mathrm{opt}}}
$$

$P$ is the power available at the terminals of GPV.

$V_{\text {opt }}$ and $I_{\text {opt }}$ are respectively the voltage and current optimal of generator PV.

And performance the converter noted $\eta_{\text {conv }}$, which is defined by (10), noting the power $P_{\text {out }}$ delivered at the 
output the converter

$$
\eta_{\text {conv }}=\frac{P_{\text {out }}}{P}
$$

Unfortunately, more the converter is complex, plus its own performance noted $\eta_{\text {conv }}$ is low. For the user, the only important overall efficiency $\eta$ of the entire chain [8] [9]:

$$
\eta=\eta_{p v} \cdot \eta_{\mathrm{MPPT}} \cdot \eta_{\mathrm{conv}}
$$

For these variables must be optimized solar system by intelligent controls (embedded system) to increase the efficiency and effectiveness of our system.

\subsection{Form Factor}

Called form factor FF, also called factor curve or fill factor, the ratio between the maximum power output $P_{\max }$ cell $\left(I_{\mathrm{opt}}, V_{\mathrm{opt}}\right)$ and the product of the short-circuit current $I_{s c}$ by the open circuit voltage Voc (that is to say the maximum power an ideal cell). The shape factor indicates the quality of the cell [10]; as it approaches the unit cell is more efficient, it is of the order of 0.7 for efficient cells; and decreases with temperature. It reflects the influence of losses by both parasitic resistances and is defined by:

$$
\begin{gathered}
\mathrm{FF}=P_{\max } /\left(V_{c o} \cdot I_{c c}\right) \\
\text { Consequently }: \mathrm{FF}=V_{\mathrm{opt}} \cdot I_{\mathrm{opt}} /\left(V_{c o} \cdot I_{c c}\right)
\end{gathered}
$$

$V_{c o}(\mathrm{~V})$ : Open circuit voltage.

$I_{c c}(\mathrm{~A})$ : The current of a short circuit.

For our system after the simulation of the influence of meteorological parameters on FF and performance are illustrated in the following Figure 15 and Figure 16.

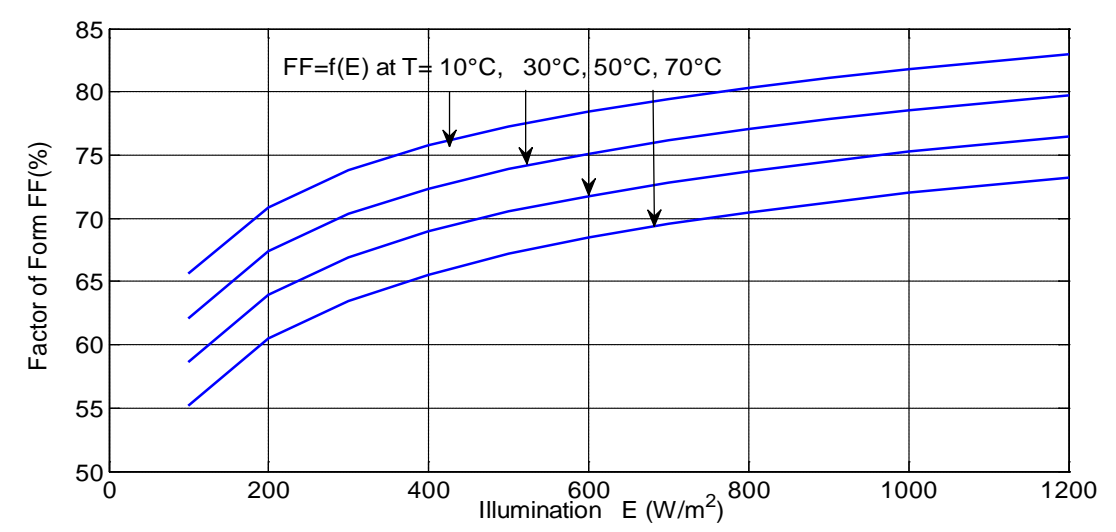

Figure 15. Variation of form factor depending of $E$ and $T$.

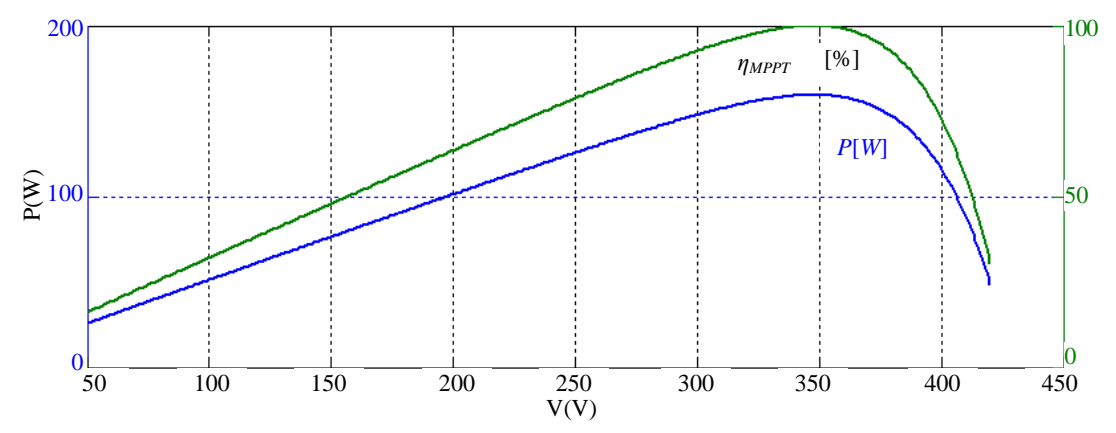

Figure 16. Power available and yield of command for different operating points. 
When illumination increases the fill factor increases. The fill factor diminishes as the temperature of the device increased. The decrease in FF with the working temperature of the device outweighs the slight increase in the short circuit current. Finally for having a clearer idea of the origins of losses and yields of each part of a chain of power for a solar system, we presented the definitions of performance and form factor to extract performance against weather conditions. In all cases it is necessary to continuously monitor the output voltage of the converter, that is to say either the voltage of the battery charger or the DC bus voltage to an inverter. In addition it is also useful to monitor the battery charge, the battery current measure, then it is easier to maximize the power output of the generator set and the converter because it is this power that is useful and not the extracted panel.

Therefore to increase the efficiency of a solar system must integrate MPPT controls for example knowing that there are different types of algorithms performing the search of maximum power point MPP [11].

\section{Conclusion}

The performance of the PV generator is evaluated according to the standard conditions (STC): irradiance 1000 $\mathrm{W} / \mathrm{m}^{2}$, and Temperature $25^{\circ} \mathrm{C}$. The performance of a PV solar system highly depends on the weather conditions, such as solar radiation, temperature and light, so does the performance of the PV generator degrade with increasing temperature, the decrease in intensity and the illumination load variations. To provide energy continuously throughout the year, a PV system must be properly sized and led by intelligent command to monitor MPPT for extracting the maximum energy. And for the simulation of DC-DC converters, we have shown by simulation that the average value of the output voltage can be adjusted by varying the duty cycle value. In perspective, this work will be continued with a practical realization of MPPT command based microcontroller and a follower by an Arduino board for increasing the efficiency of a solar system to extract the maximum energy.

\section{References}

[1] El Alami, M., Habibi, M. and Bri, S. (2013) Parameters Efficiency of Solar Energy. International Journal of Emerging Trends in Engineering and Development-IJETED, 4, 175-186.

[2] Villalva, M.G., Gazoli, J.R. and Filho, E.R. (2009) Comprehensive Approach to Modeling and Simulation of Photovoltaic Arrays. IEEE Transactions on Power Electronics, 24, 1198-1208.

[3] Hoque, A.K. and Wahid, A. (2000) New Mathematical Model of a Photovoltaic Generator. Journal of Electrical Engineering, EE 28, 8p.

[4] El Alami, M., Habibi, M. and Bri, S. (2014) Modelling of Solar System by Newton Raphson Method, MPPT Algorithm. European Journal of Scientific Research, EJSR, 120, 264-276.

[5] Yu, G.J., Jung, Y.S., Choi, J.Y., Choy, I., Song, J.H. and Kim, G.S. (2002) A Novel Two-Mode MPPT Control Algorithm Based on Comparative Study of Existing Algorithms. Conference Record of the Twenty-Ninth IEEE Photovoltaic Specialists Conference, 19-24 May 2002, 1531-1534.

[6] Zhou, C., Ridley, R.B. and Lee, F.C. (1990) Design and Analysis of Hysteretic Boost Power Factor Circuit. Annual IEEE Power Electronics Specialists Conference, San Antonio, 800-801. http://dx.doi.org/10.1109/PESC.1990.131271

[7] Prasad, A.R., Ziogas, P.D. and Manias, S. (1992) A New Active Power Factor Correction Method for Single-Phase Buck-Boost AC-DC Converter. Conference Proceedings of Seventh Annual Applied Power Electronics Conference and Exposition, Boston, 23-27 February 1992, 814-820.

[8] Hohm, D.P. and Ropp, M.E. (2003) Comparative Study of Maximum Power Point Tracking Algorithms. Progress in Photovoltaics: Research and Applications, 11, 47-62. http://dx.doi.org/10.1002/pip.459

[9] Jain, S. and Agarwal, V. (2007) Comparison of the Performance of Maximum Power Point Tracking Schemes Applied to Single-Stage Grid-Connected Photovoltaic Systems. IET Electric Power Applications, 1, 753-762. http://dx.doi.org/10.1049/iet-epa:20060475

[10] Nielson, G.N., Okandan, M., Resnick, P., Cruz-Campa, J.L., Pluym, T., Clews, P.J., Steenbergen, E. and Gupta, V.P. (2009) Microscale C-Si (C)PV Cells for Low-Cost Power. 34th IEEE Photovoltaic Specialists Conference (PVSC), Philadelphia, 7-12 June 2009, 1816-1821.

[11] Femia, N., Pétrone, G., Spagnuolo, G. and Vitelli, M. (2005) Optimization of Perturb and Observe Maximum Power Point Tracking Method. IEEE Transactions on Power Electronics, 20, 963-973. 
Scientific Research Publishing (SCIRP) is one of the largest Open Access journal publishers. It is currently publishing more than 200 open access, online, peer-reviewed journals covering a wide range of academic disciplines. SCIRP serves the worldwide academic communities and contributes to the progress and application of science with its publication.

Other selected journals from SCIRP are listed as below. Submit your manuscript to us via either submit@scirp.org or Online Submission Portal.
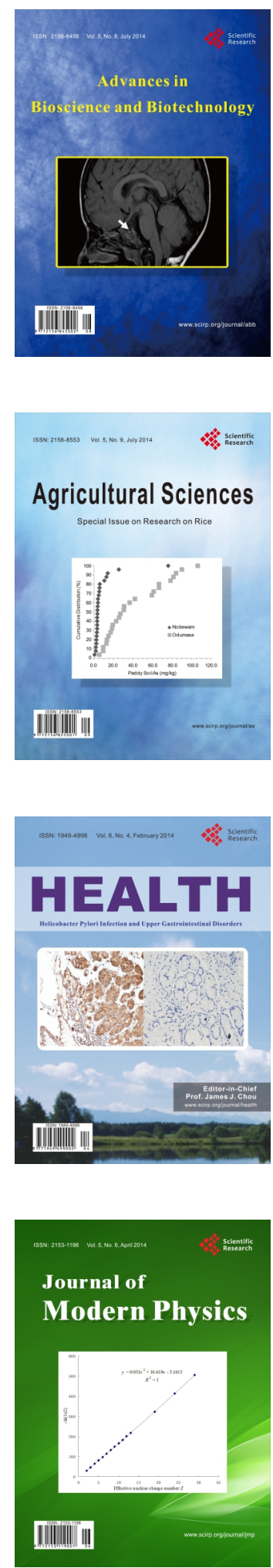
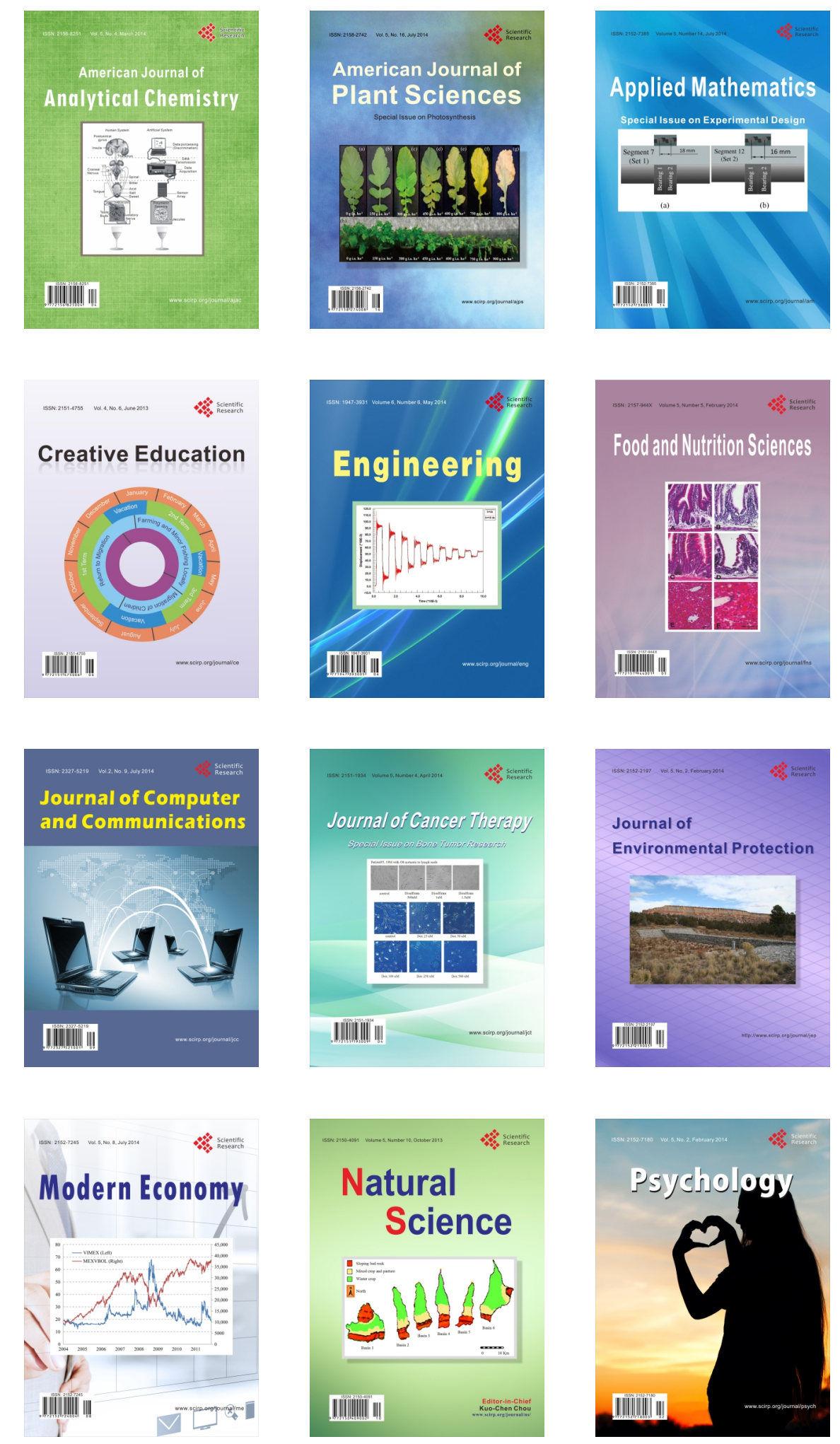